\title{
Community acquired viral hepatitis B and C in the United States
}

\author{
M J Alter
}

\begin{abstract}
In the United States, most reported cases of hepatitis $B$ occur in adults as a result of behavioural, lifestyle, or occupational exposures, but a significant number of children also become infected in well defined settings. Although only $1-3 \%$ of acute hepatitis $B$ virus (HBV) infections occur in children under 5 years of age, they account for $20-30 \%$ of all chronic infections. A new strategy for HBV prevention in the USA includes integration of HBV vaccine into childhood immunisation schedules. Vaccination strategies that target high risk groups have not been effective. To determine the frequency and severity of community acquired chronic hepatitis $C$, patients with acute non-A, non-B hepatitis identified in four sentinel counties in the United States were followed prospectively. Hepatitis $C$ virus (HCV) infection was found in $106(82 \%)$ of 130 patients. Ninety three per cent of the HCV positive patients had a risk factor for their infection: $59 \%$ parenteral, $6 \%$ sexual or household, and $28 \%$ low socioeconomic level. Chronic hepatitis developed in $62 \%$, independently of the risk factor for infection. HCV-RNA persisted in most patients, including those with biochemical resolution of their hepatitis. This study suggests that HCV may be a major cause of liver disease and persistent viraemia in the United States.
\end{abstract}

(Gut 1993; supplement: S17-S19)

\section{HBV: epidemiology}

In the United States, most reported cases of hepatitis B occur in adults as a result of behavioural, lifestyle, or occupational exposures. ${ }^{1}$ However, a significant number of children become infected in well defined settings, and the epidemiology of these infections is quite different from infections acquired by adults. ${ }^{2}$ Because over $90 \%$ of childhood infections are asymptomatic, the true incidence of childhood disease is not accurately represented by national surveillance data which monitor reported cases of clinically apparent disease. It is estimated that 200 000-300 000 hepatitis B virus (HBV) infections have occurred annually in the United States since 1979. Although only $1-3 \%$ of these infections occur in children under 5 years of age, they account for $20-30 \%$ of all chronic infections.

Among adults, sexual activity (both homosexual and heterosexual) is the most commonly reported risk factor for $\mathrm{HBV}$ infection. ${ }^{1}$ Between 1985 and 1988, however, the number of cases of hepatitis $B$ in homosexual men declined by $62 \%$; in contrast, the number of cases of $\mathrm{HBV}$ infection as a result of heterosexual activity increased by $38 \%$. In 1990, heterosexual activity accounted for $27 \%$ of cases, homosexual activity for $11 \%$, and injecting drug use for $14 \%$ (Centers for Disease Control, unpublished data).

Adults in general, and groups such as injecting drug users and sexually transmitted disease (STD) patients in particular, have been extremely difficult to reach for delivery of vaccine. One programme designed to provide $\mathrm{HBV}$ vaccine free of charge to susceptible drug users and their sexual partners ${ }^{3}$ found that, of the drug users screened at a variety of community access sites, $54 \%$ had been injecting drugs for at least five years. Of the long term drug users, $95 \%$ had evidence of previous HBV infection and, overall, only $24 \%$ of drug users who were accessed during the programme were susceptible to HBV infection and candidates for vaccination. Factors associated with susceptibility included young age (less than 25 years old), less than two years of drug use, infrequent drug use (less than once a month), and a negative history of imprisonment. In addition, only $39 \%$ of those susceptible received at least two doses of vaccine over a six month period of intensive follow up. In contrast, sexual partners of drug users were less likely to have serological evidence of infection ( $79 \%$ were susceptible) and were more likely to receive at least two doses of vaccine $(54 \%)$. HBV vaccine programmes have been evaluated recently in two sexually transmitted disease clinic populations. ${ }^{4}$ Results of prevaccination serological screening showed that $20-30 \%$ had prior evidence of $\mathrm{HBV}$ infection. Only $14 \%$ of the population received two doses of vaccine, and only $4 \%$ completed the three dose regimen.

An additional problem with the high risk group vaccination strategy for the prevention of HBV infection is that at least $30 \%$ of patients cannot be associated with an identifiable risk factor, which places them out of reach of an immunisation strategy that targets only high risk groups. Half of these patients have surrogate factors for high risk behaviour such as a history of other sexually transmitted diseases. These patients tend to belong to minority populations and have characteristics associated with low socioeconomic level. ${ }^{15}$

Ninety per cent of the cases of HBV infection reported in the United States are among adults, but $9 \%$ are among adolescents 
11-19 years old. Most health care providers probably overlook this age group when considering persons at risk of infection. ${ }^{2}$ Of the cases of HBV in adolescents with a known source for their infection, $50 \%$ can be attributed to sexual or other person to person contact, and $47 \%$ to injecting drug use.

CONTROL OF HBV INFECTION

Control of HBV infection is possible with the appropriate use of HBV vaccines. However, as vaccination strategies that target high risk groups have not been effective, the United States has recently adopted a comprehensive strategy for eliminating transmission of $\mathrm{HBV}$ which includes (a) universal HB surface antigen (HBsAg) screening of pregnant women with immunoprophylaxis of infants born to potentially infectious mothers to prevent perinatal infections; and (b) the integration of HBV vaccine into current childhood immunisation schedules to prevent early childhood infections in high risk populations and to provide immunity to teenagers and adults before becoming at risk of infection. ${ }^{6}$

\section{Hepatitis C}

Studies using first generation serological assays for antibody to the hepatitis $C$ virus (anti$\mathrm{HCV}$ ) have shown that $\mathrm{HCV}$ is responsible for most community-acquired non-A, non-B (NANB) hepatitis in the United States. ${ }^{7}$ In this setting, the relative importance of parenteral (transfusions, drug use, and occupation), sexual, and household exposures in the transmission of this disease have been shown by case-control studies, as have the characteristics associated with low socioeconomic level. ${ }^{58}$

\section{COMMUNITY ACQUIRED HCV}

One of the most significant features of $\mathrm{HCV}$ infection is the frequency with which patients develop chronic liver disease, although this has been well studied only in those with transfusion associated disease. ${ }^{910}$ To determine the frequency and severity of community acquired chronic HCV, patients with acute NANB hepatitis identified in 1985-1986 in four sentinel counties in the United States were followed prospectively. ${ }^{11}$ Three markers were used to detect $\mathrm{HCV}$ infection in serum: antibody to HCV (anti-HCV) by second generation serological assays; ${ }^{12}$ HCV-RNA by polymerase chain reaction; ${ }^{13}$ and antibody to HCV antigen (anti-HVCAg) by fluorescent antibody blocking assay. ${ }^{14}$

HCV infection was found in $106(82 \%)$ of 130 patients; $72 \%$ were positive for anti-HCV and $10 \%$ were positive only for HCV-RNA or anti-HCVAg. Ninety three per cent of the HCV positive patients had a risk factor for their infection; $59 \%$ parenteral, $6 \%$ sexual or household, and $28 \%$ low socioeconomic level.

Chronic hepatitis developed in $62 \%$ of the $\mathrm{HCV}$ infected patients independent of the risk factor for infection. Chronic hepatitis C was found in $67 \%$ of patients with a history of blood transfusion, $60 \%$ of injecting drug users, $60 \%$ of patients with occupational exposure to blood, $83 \%$ of patients with sexual or household exposure, $61 \%$ of patients associated with low socioeconomic level, and $43 \%$ of patients with no risk factor ( $p>0.05$ ).

Liver biopsies were performed in 30 patients with chronic hepatitis C. Of these, $10(33 \%)$ had chronic active hepatitis (CAH), one of whom also had cirrhosis, $13(43 \%)$ had chronic persistent hepatitis $(\mathrm{CPH})$, and six $(20 \%)$ had chronic lobular hepatitis (CLH). One patient had portal fibrosis without other histopathological findings; this patient was positive for HCV-RNA. Repeat biopsies were performed in 10 patients; one patient progressed from $\mathrm{CPH}$ to $\mathrm{CAH}$ over 32 months, and a second patient went from CLH to $\mathrm{CPH}$ over 33 months. All patients with a history of blood transfusion who underwent biopsy had $\mathrm{CAH}$ compared with $22 \%$ of patients with other risk factors for infection $(\mathrm{p}<0.01)$.

HCV-RNA was detected 42-48 months after the onset of illness in 12 of 13 chronic hepatitis C patients tested; in two patients, HCV-RNA positivity was intermittent. Persistent $\mathrm{HCV}$ infection also occurred in patients without biochemical evidence of chronic liver inflammation. Testing for HCVRNA was performed on samples collected 42-48 months after acute onset in 15 patients with persistently normal alanine aminotransferase activity throughout follow up; all were HCV-RNA positive. In four patients, detection of HCV-RNA was intermittent.

\section{Conclusion}

This study suggests that HCV may be a major cause of chronic liver disease in the United States. Furthermore, patients with biochemical resolution of their hepatitis may remain positive for HCV-RNA, suggesting that persistent infection in the absence of liver imflammation is similar to, but occurs at a much higher rate, than in persons infected with HBV. Thus, there is an urgent need for the development of preventive and treatment measures for persons in all risk groups.

1 Alter MJ, Hadler SC, Margolis HS, et al. The changing epidemiology of hepatitis $\mathrm{B}$ in the United States. Need for alternative vaccination strategies. $\Im A M A$ 1990; 263: 1218-22.

2 Margolis HS, Alter MJ, Hadler SC. Hepatitis B: Evolving epidemiology and implications for control. Semin Liver Dis 1992; 11: 84-92.

3 Schatz G, Hadler S, McCarthey J, et al. Outreach to needle users and sexual contacts: a multi-year, community-wide hepatitis B/delta hepatitis control program in Worcester, Massachusetts (abstract). In: Coursaget P, Tong MJ, eds Progress in hepatitis B immunization. London: John Libbey, 1990: 533.

4 Centers for Disease Control. Successful strategies in adult immunization. MMWR 1991; 40: 700-9.

5 Alter MJ, Coleman PJ, Alexander WJ, et al. Importance of heterosexual activity in the transmission of hepatitis $B$ and non-A, non-B hepatitis. $¥ A M A$ 1989; 262: 1201-5.

6 Centers for Disease Control. Hepatitis B virus: a comprehensive strategy for eliminating transmission in the United States through universal childhood vaccination: recommendations of the Immunization Practices Advisory Com 40(no RR-13): 1-19. 
7 Alter MJ, Hadler SC, Judson FN, et al. Risk factors for acute non-A, non-B hepatitis in the United States and association with hepatitis $\mathrm{C}$ virus antibody. $\mathscr{f} A M A$ 1990; 264: 2231-5.

8 Alter MJ, Gerety RJ, Smallwood L, et al. Sporadic non-A, non-B hepatitis: frequency and epidemiology in an urban United States population. F Infect Dis 1982; 145: 886-93.

9 Alter HJ, Jett BW, Polito AJ, et al. Analysis of the role of hepatitis $C$ virus in transfusion-associated hepatitis. In: Hollinger FB, Lemon SM, Margolis HS, eds. Viral hepatitis and liver disease. Baltimore: Williams and Wilkins, 1991; 396-402.

10 Aach $\mathrm{RD}$, Stevens $\mathrm{CE}$, Hollinger $\mathrm{FB}$, et al. Hepatitis $\mathrm{C}$ virus infection in post-transfusion hepatitis. An analysis with first- and second-generation assays. N Engl f Med 1991; 325: 1325-9.
11 Alter MJ, Margolis HS, Krawczynski K, et al. The natural history of community-acquired hepatitis $C$ in the United States. N Engl. F Med 1992; 327: 1899-905.

12 Mimms L, Vallari D, Ducharme L, Holland P, Kuramoto IK Z L, Vallari D, Ducharme L, Holland P, Kuramoto $\mathrm{IK}$, Zeldis J. Specificity of anti-HCV ELISA assessed by reactivity to three immunodominant $\mathrm{HCV}$ regions. Lancet

13 Beach MJ, Meeks EL, Mimms LT, et al. Temporal relationships of hepatitis C virus RNA and antibody responses following experimental infection of chimpanzees. $\mathcal{f}$ Med Virol 1992; 36: 226-37.

14 Krawczynski K, Beach MJ, Bradley DW, et al. Hepatitis C virus antigen in hepatocytes: immunomorphologic detection and identification. Gastroenterology 1992; 103: $622-9$. 